\title{
Determinants of participation in colonoscopic screening by siblings of colorectal cancer patients in France
}

Myriam Taouqi ${ }^{1}$, Isabelle Ingrand ${ }^{2}$, Michel Beauchant ${ }^{3}$, Virginie Migeot ${ }^{1}$ and Pierre Ingrand*1,2

\begin{abstract}
Background: Targeted colonosocopic screening is recommended for first-degree relatives of colorectal cancer patients diagnosed before the age of 60 and offers the possibility of reducing morbidity and mortality, but participation remains too low. The objective of this study was to determine in a French population the factors that affect siblings' participation in screening, notably those relating to the individuals, their medical care, their family and their social network.

Methods: A cross sectional survey was conducted in siblings of index patients having undergone surgery for colorectal cancer between 1999 and 2002 in two French counties. Siblings were contacted during 2007 and 2008 through the index patient. The factors affecting participation in colonoscopic screening were studied by logistic regression taking into account family cluster effect.

Results: 172 siblings of 74 index cases were included. The declared rate of undergoing at least one colonoscopy among siblings was $66 \% ; 95 \% \mathrm{Cl} 59-73 \%$. Five variables were independently associated with colonoscopic screening: perceiving fewer barriers to screening $(\mathrm{OR}=3.2 ; 95 \% \mathrm{Cl} 1.2-8.5)$, having received the recommendation to undergo screening from a physician $(O R=4.9 ; 1.7-13.7)$, perceiving centres practising colonoscopy as more accessible $(O R=3.2$, 1.3-7.8), having discussed screening with all siblings $(\mathrm{OR}=3.9 ; 1.6-9.6)$ and being a member of an association ( $\mathrm{OR}=2.6$; 1.0-6.6).

Conclusions: The factors independently associated with participation in CRC screening by an individual at increased risk belonged to each of four dimensions relating to his individual psychosocial characteristics, to his relationship with a physician, within the family and social environment. The relevance of these results to clinical practice may help to improve compliance to recommendations in a global preventive strategy including all stages of the information pathway from the physician to the index patient and his relatives.
\end{abstract}

\section{Background}

Approximately $25 \%$ of new colorectal cancer (CRC) cases occur in individuals who are at higher than average risk of the disease [1]. A recent meta-analysis showed that firstdegree relatives (FDRs) of CRC patients, especially brothers and sisters, have twice the risk of developing the illness as compared with the general population [2]. Colonoscopic screening of FDRs of CRC patients offers the possibility of reducing morbidity and mortality $[3,4]$. Screening recommendations in France, advise colono-

* Correspondence: pierre.ingrand@univ-poitiers.fr

1 Public Health; Centre Hospitalier Universitaire de Poitiers; Université de Poitiers; 6 rue de la Milétrie BP 199; 86005 Poitiers Cedex, France

Full list of author information is available at the end of the article scopic screening for subjects at increased risk owing to a family history of CRC occurring in one FDR below the age of 60 or in two or more FDRs irrespective of age of onset [5]. High-risk individuals because of first-degree relatives with CRC or colorectal adenoma before the age of 60 are excluded from organized screening which concerns medium risk individuals, that is to say all subjects aged 45 or more, even if they have never had digestive disorders. As in other countries, high-risk individuals are not systematically informed about their increased CRC risk in France. Screening recommendations addressing high-risk individuals also differ from those aimed at very high risk subjects, belonging to families with a hereditary 
form of CRC (FAP or HNPCC). Recent data indicate that FDRs of CRC patients significantly under-use screening, the participation rate lying between 30 and 64\% [6$9,11,12]$.

Until now, few studies on the factors associated with participation in CRC screening by FDRs, recruited subjects at increased risk as defined by the recommendations currently in force (definition of family history, age of index patient, age of FDR and type of examination recommended for this population) [13]. In these studies, relationships with a physician $[6,8,9]$ and within the family $[6,9]$ were consistently associated with participation in screening but little attention was paid to support from friends and colleagues [6]. Finally, the subjects who perceived the fewest barriers to screening were also the most likely to participate $[6,7,9]$. These four major factors that influence participation in screening by FDRs at risk of CRC - individual characteristics, recommendation from a physician, relationships within the family and the social environment - should therefore be the subject of a comprehensive study [6]. The theoretical framework used in our study was drawn up after a review of the literature about the potential relevance of validated models, corroborated by analysis of interviews carried out during a preliminary qualitative study [14]. The Health Belief Model (HBM) [15] has proved its relevance in the study of individual preventive health behaviour, especially in colorectal cancer [6-9,11] and interviews [14] brought out the four major constructs of the HBM - perceived susceptibility to and severity of CRC, perceived benefits of and barriers to participating in screening - and also referred to motivation to safeguard health [16,17]. These interviews also pointed out a normative dimension (how much the person feels social pressure to do something), which is a component of the Theory of Reasoned Action (TRA), another psychosocial model of preventive behaviour [18] which, to our knowledge, has not been studied in the context of targeted screening. A third model, the Social Network Theory (SNT) as applied to health was added to our conceptual framework to study the role of family and social environment. This model provides the structural (quantitative aspects such as number of ties and frequency of contact with ties) and functional aspects, including emotional support (receiving reassurance that one is loved and cared for) and material support (assistance provided by social network ties) [19].

To our knowledge, since the general implementation of the colorectal screening recommendations, no research has included all the key concepts derived from the three heretofore mentioned models as well as relationships within the family, the doctor-patient relationship, and factors such as perception of healthcare organization and fatalism $[20,21]$. The aim of this study was to identify and quantify the respective roles of these factors in determin- ing participation in screening by the siblings of patients below the age of 60 operated on in France for CRC.

\section{Methods}

The study's design was that of a cross sectional survey of siblings, taking into account a reasonable five-year delay between the index patients' CRC first surgery and the undertaking of colonoscopy surveillance among siblings. The index patients, retrospectively identified from hospital discharge records, responded to the following inclusion criteria: having undergone a first surgical intervention for CRC between 1999 and 2002 in a hospital in either of two counties in the west of France, namely La Vienne and Les Deux-Sèvres (population 743,416 inhabitants), being not more than 60 years old at the time of surgery, having an adequate command of French, having at least one brother or sister, and having the consent of both surgeon and patient (or surviving spouse in the case of death). Index patients were excluded in the case of hereditary cancer confirmed by genetic analysis or chronic inflammatory bowel disease. Siblings, identified through the index patients, responded to the following inclusion criteria: residing in metropolitan France, having at least one ancestor in common with the index patient, having adequate command of French, and having given signed written consent. Siblings were excluded from the study if they fell outside the criteria for screening as defined by the recommendations: personal history of $\mathrm{CRC}$ or chronic inflammatory bowel disease, colonoscopy performed in the context of symptoms, falling outside the age range intended by the French recommendations (less than 45 years old or being more than 5 years younger than the index patient at the time of diagnosis). The initial contact with the index patients - or their spouses - and their siblings was made by the operating surgeon, with the index patients' or surviving spouses' written consent, all in the strictest respect of medical confidentiality.

Selected variables were included in the questionnaire (Figure 1). The items from the HBM were translated from Champion's scale [16] and its subsequent revisions $[17,21]$. Fatalism was measured by four items adapted from Powe's index of fatalism [20]. Multi-item scales were scored by summing the responses given. The TRA was approached via its twin components of attitudes (personal) and subjective norms (social) [18]. Health-linked behaviours were also recorded $[9,10]$. Variables relating to the medical context included the fact of having received the recommendation to undergo screening from a physician and the perceived ease of access to centres practising colonoscopy in terms of geographic location and waiting times. Also recorded were the FDR's characteristics and family-related variables. Among social network scores, the structural support score was calculated 


\begin{tabular}{|c|}
\hline $\begin{array}{c}\text { Individual } \\
\text { psychosocial } \\
\text { variables }\end{array}$ \\
Health Belief Model \\
- Severity score \\
- Vulnerability score \\
- Benefits score \\
- Obstacles score \\
- Motivations score \\
Fatalism \\
- Fatalism score \\
Theory of Planned \\
Behaviour \\
- Attitudes score \\
- Subjective norms \\
Health behaviours \\
- Smoking status \\
- Other prevention or \\
screening behaviours \\
\end{tabular}
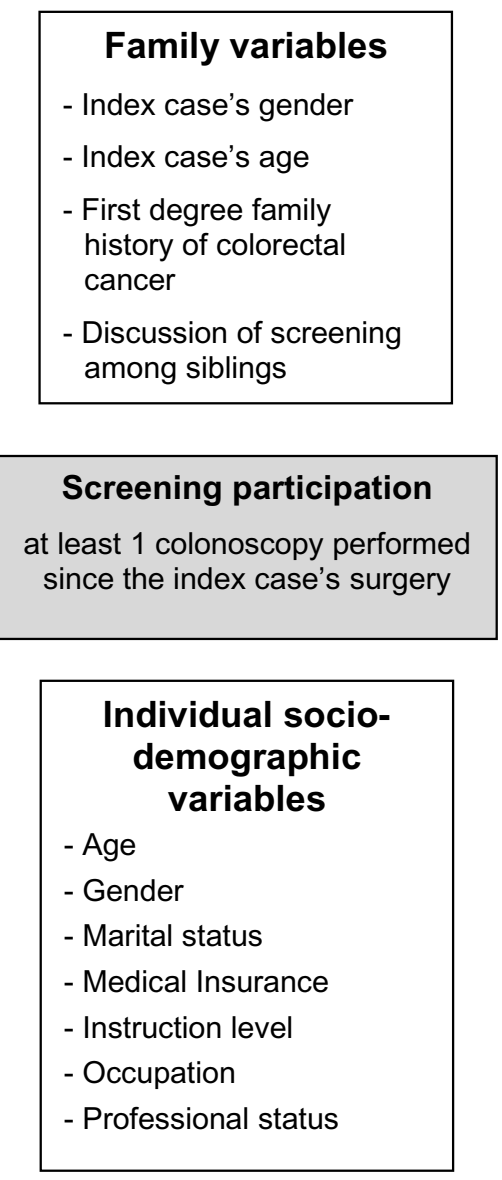

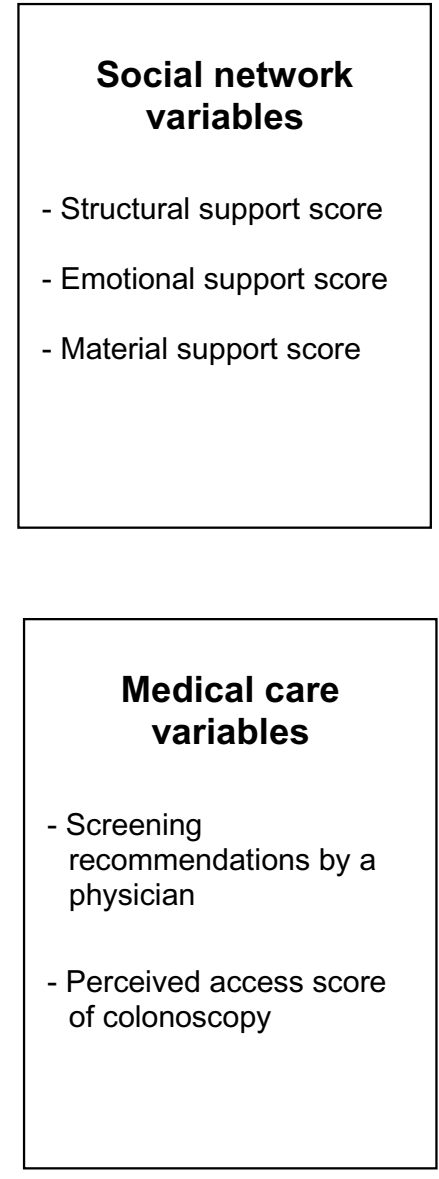

Figure 1 Summary of variables and their respective dimensions included in the analysis of participation of siblings to colonoscopic screening.

from three items: marital status, contact with friends and family, and being a member of an association [22]. The emotional support score incorporated four items relating to the availability of friends and relatives to talk about personal or health problems; a final item dealt with material support [19]. The study received the approval of the French regulatory authorities.

The outcome was participation in screening, defined as reporting at least one colonoscopy performed since the index patient's original surgery. The data were collected between March 2007 and February 2008 by means of a self-administered questionnaire sent by post to siblings. In case of non-response, a written reminder was sent, followed by three telephone calls. Questionnaires missing responses in more than half the variables of interest on any given scale were discounted. In calculating a score, when at least half the items were answered, and when the unanswered questions were of similar content to allow an extrapolation, the average of these answers was attributed to the non-answered items.
The univariate statistical analysis compared participating with non-participating individuals using a Pearson's chi-square test or a Fisher's exact test for qualitative variables, a parametric test comparing means for quantitative variables and a Mann-Whitney non-parametric test for ordered variables, with a significance level of $5 \%$. For quantitative variables, prior to logistic regression analysis, the hypothesis of linearity in the logit was assessed using the polynomial method and the Box-Tidwell transformation [23]. In the case of non-linearity, categorization into two classes defined by the median was carried out. The correlation between variables was computed using Spearman's correlation matrix. The variables selected at the level of $\mathrm{P}<0.25$ were entered into the initial multivariate model, with the exception of those variables for which more than $10 \%$ of the data were missing. The multivariate analysis, performed on a database with no missing data for the retained variables, followed a descending stepwise procedure, first by dimension, then on all the selected variables. Three variables were kept for 
adjustment: age, sex and education level. The logistic regression took into account the cluster effect resulting from the inclusion of several individuals belonging to the same family. The search for confounding factors and factors of colinearity was carried out by monitoring the variation of beta estimators and standard errors at each stage of the procedure. The search for relevant interactions was performed on the final model. The adequacy of the final model was confirmed by the Hosmer-Lemeshow test.

\section{Results}

Of the 251 index patients identified, 88 (35\%) were included (Figure 2). Of the 272 brothers and sisters whose details were provided, a total of 172 (63\%) were included. These were the siblings of 74 index patients and almost half of them were the latters' only brother or sister. Of the 172 brothers and sisters, 66\% (95\% CI 59\% to 73\%) reported that they participated in screening. Taking into account 31 siblings who refused to participate in the study and 32 non- respondents (although probably not all of them did meet the inclusion criteria), a low estimate of the participation rate was $45 \%$.

Univariate analyses of associations between participation of siblings in screening and socio-demographic characteristics, individual psychosocial factors, medical factors and social network factors are presented in tables 1, 2 and 3. No socio-demographic characteristic was significantly associated with participation in screening at the $5 \%$ level. Among the individual psychosocial factors, the mean scores for perceived susceptibility to CRC ( $P=$ $0.0026)$, motivation to safeguard health $(P=0.025)$ attitudes $(P=0.024)$ and perceived benefits of screening $(P=$ 0.0004 ) were significantly higher in subjects who participated in screening. This group perceived fewer barriers to screening $\left(P<10^{-4}\right)$. These differences were observed for each of the items included in the benefits score (reassurance, lessening of anxiety, early detection of an abnormality or cancer, diminution of the risk of mutilating surgery or dying of CRC) and barriers score (embarrassment to talk about CRC and undergo regular checks, additional anxiety, unpleasant nature of the examination, time and cost implications) respectively. Fatalism seemed somewhat less marked in those who participated, but not to the extent of reaching the level of significance $(P=$ 0.058). The screened brothers and sisters were more often non-smokers $(P=0.038)$, were more likely to have been told about the screening recommendations by a physician $\left(P<10^{-4}\right)$, had a more favourable impression of the accessibility of colonoscopy $(P=0.0011)$, had more often discussed screening with all their brothers and sisters $\left(P<10^{-4}\right)$ and had a higher mean score for emotional support $(P=0.039)$. The screened siblings were more likely to be a member of an association, but not to the extent of reaching the level of significance $(P=0.055)$.
The factors favouring siblings' participation in screening derived from the multivariate logistic regression are shown in table 4 . The subjects who perceived less barriers to screening $(\mathrm{OR}=3.2$ ), had received the recommendations for screening from a physician $(\mathrm{OR}=4.9)$, perceived colonoscopy as more accessible $(\mathrm{OR}=3.2)$, had discussed screening with all their brothers and sisters $(\mathrm{OR}=3.9)$ and were members of an association $(\mathrm{OR}=2.6)$ were significantly more likely to participate in screening.

\section{Discussion}

This study showed that the factors independently associated with participation in CRC screening by an individual at increased risk belonged to each of four dimensions relating to his individual psychosocial characteristics and his relationship with a physician, within the family and social environment. Univariate analysis confirmed that screening participants were more likely to be non-smokers [10], a factor linked to health behaviour. Their scores for perceived susceptibility to CRC [7], perceived benefits of screening and motivation to safeguard health were higher, whilst their scores for perceived barriers to screening $[6,7,9]$ and fatalism were lower. Their perception of the usefulness of screening and in particular their sensitivity to social pressure was higher. More often they had received recommendations from their physicians $[6,8,9]$ and their score for perceived accessibility of colonoscopy centres was higher. A significant number of them had discussed screening with their brothers and sisters [6,9] and were members of an association. Their score for emotional support was higher. Factors that had not previously been studied in the context of targeted CRC screening were identified (fatalism, accessibility of centres practising colonoscopy, social pressure, being a member of an association and support of a friend or colleague).

The study population was defined as subjects at increased risk of CRC on account of their family history, as defined by the current recommendations. The CRC patient's age and the histological diagnosis of the tumour were taken from the medical record, thus permitting an accurate definition of subjects at increased risk of CRC; this is in contrast to several studies relying on self-reporting of family history [13]. FDRs who had undergone colonoscopy on account of symptoms or in the context of surveillance relating to their own medical history were excluded from the analysis in order to avoid artificially increasing the rate of participation in screening. Despite this, we found a participation rate of $66 \%$, which is relatively high compared with data in the literature [6-12]. However, the results must be interpreted in the light of the inherent limits of a declarative study. We suspected two sources of selection bias in our study. First, index patients' acceptance to let us contact their relatives might 


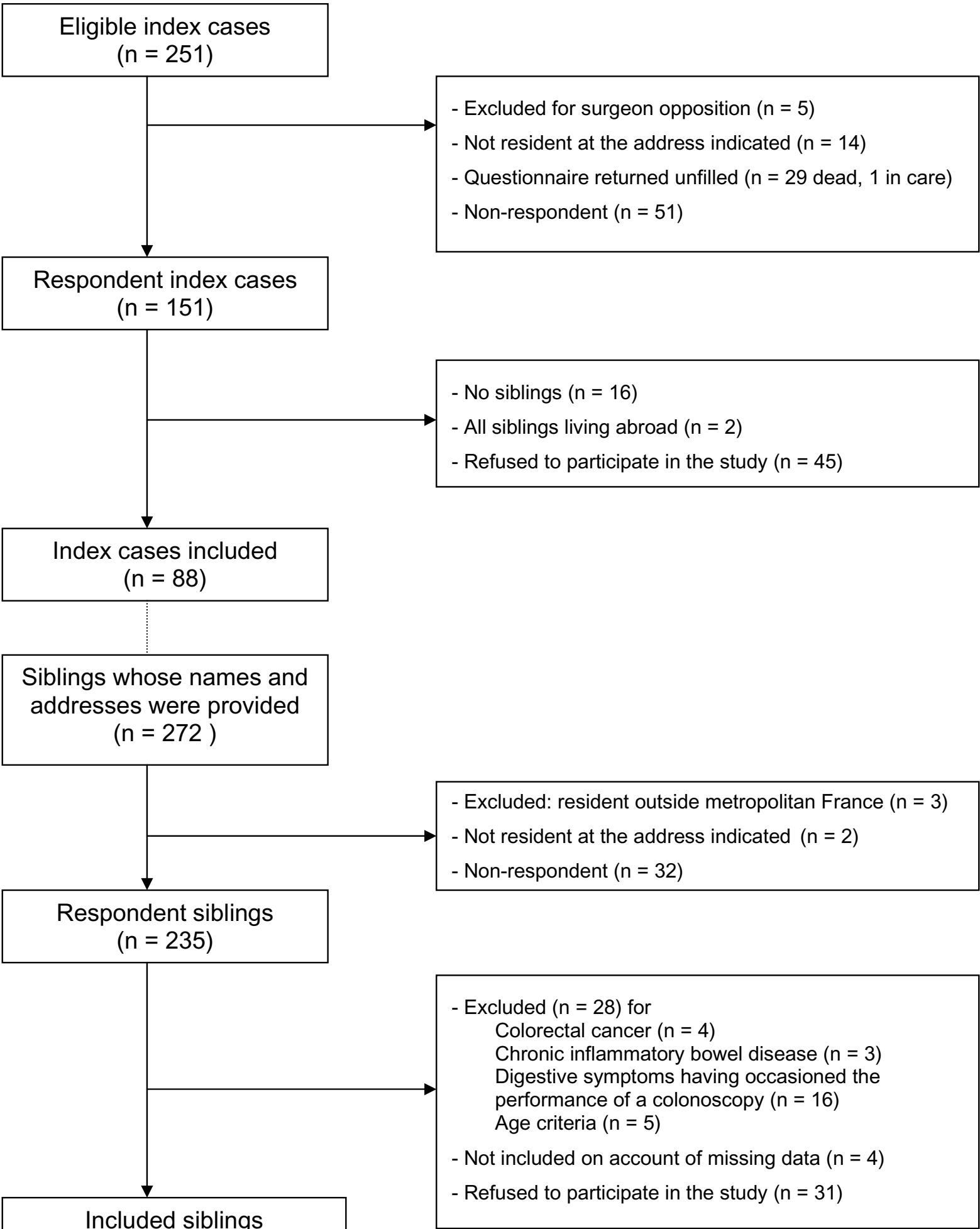
$(n=172$, from 74 families $)$ 
Table 1: Univariate analysis of socio-demographic characteristics of index patients' siblings and their association with participation in colonoscopic screening.

\begin{tabular}{|c|c|c|c|c|}
\hline & $\begin{array}{c}\text { Total } \\
(n=172)\end{array}$ & $\begin{array}{c}\text { Participators } \\
\text { (n=114) }\end{array}$ & $\begin{array}{l}\text { Non-participators } \\
\qquad(\mathrm{n}=58)\end{array}$ & $P$ \\
\hline Sex: female & $87(50.6)$ & $59(51.8)$ & $28(48.3)$ & 0.67 \\
\hline Age & $59.8(9.2)$ & $59.1(8.2)$ & $61.2(10.8)$ & 0.21 \\
\hline Married or living with someone & $135(79.0)$ & $89(78.8)$ & $46(79.3)$ & 0.93 \\
\hline Health insurance & & & & - \\
\hline Social Security with top-up & $165(95.9)$ & $110(96.4)$ & $55(94.8)$ & \\
\hline Social Security without top-up & $4(2.3)$ & $2(1.8)$ & $2(3.5)$ & \\
\hline Public health care & $3(1.7)$ & $2(1.8)$ & $1(1.7)$ & \\
\hline Level of education & & & & 0.12 \\
\hline None or basic school-leaving certificate & $80(46.5)$ & $50(43.9)$ & $30(51.7)$ & \\
\hline Brevet (college) & $12(7.0)$ & $7(6.1)$ & $5(8.6)$ & \\
\hline Professional studies & $53(30.8)$ & $35(30.7)$ & $18(31.0)$ & \\
\hline Baccalaureate & $10(5.8)$ & $7(6.1)$ & $3(5.2)$ & \\
\hline Higher education diploma & $17(9.9)$ & $15(13.2)$ & $2(3.5)$ & \\
\hline Profession & & & & 0.74 \\
\hline Farmer & $15(8.9)$ & $10(8.9)$ & $5(8.9)$ & \\
\hline Self-employed & $9(5.4)$ & $5(4.5)$ & $4(7.1)$ & \\
\hline Management & $17(10.1)$ & $13(11.6)$ & $4(7.1)$ & \\
\hline Intermediate & $21(12.5)$ & $15(13.4)$ & $6(10.7)$ & \\
\hline Employee & $48(28.6)$ & $35(31.2)$ & $13(23.2)$ & \\
\hline Manual worker & $36(21.4)$ & $22(19.6)$ & $14(25.0)$ & \\
\hline Retired (profession not given) & $14(8.3)$ & $8(7.1)$ & $6(10.7)$ & \\
\hline No professional activity & $8(4.8)$ & $4(3.6)$ & $4(7.1)$ & \\
\hline Professional status & & & & 0.85 \\
\hline Unemployed & $6(3.5)$ & $5(4.4)$ & $1(1.7)$ & \\
\hline Housewife & $8(4.7)$ & $6(5.3)$ & $2(3.4)$ & \\
\hline Retired & $93(54.4)$ & $61(54.0)$ & $32(55.2)$ & \\
\hline Working & $64(37.4)$ & $41(36.3)$ & $23(39.7)$ & \\
\hline
\end{tabular}

have introduced a bias towards an overrepresentation of families with good interrelationship (which has been identified as a determinant of participation in colonoscopic screening). Second, we may postulate that those relatives who declined participation in the study might likely have a lower concern with screening. Thus results may be biased directed towards an overestimated adherence.

The passing on of information by a physician was the factor most strongly associated with participation. This result has been found in several studies, be it targeted $[6,8,9]$ or generalized mass screening, and it is potentially at this level that interventions designed to increase screening participation should be implemented [24,25]. In the context of targeted screening, the relationships within the family have a very specific impact and are equally predictive of the behaviour of FDRs $[6,9]$. Discussion about screening amongst siblings involves the index patient divulging his illness and being educated to play the role of passing on medical information about the increased risk and about screening, two aspects that are difficult to address [12,25] since as for other hereditary pathologies (familial hypercholesterolaemia [26], breast cancer, melanoma ...), physicians are not authorized to contact their patients' FDRs directly. In order to prevent under-diagnosis in their relatives, index patients, assum- 
Table 2: Univariate analysis of individual psychosocial factors of index patients' siblings and their association with participation in colonoscopic screening.

\begin{tabular}{|c|c|c|c|c|}
\hline & $\begin{array}{c}\text { Total } \\
(n=172)\end{array}$ & $\begin{array}{c}\text { Participators } \\
\text { (n=114) }\end{array}$ & $\begin{array}{l}\text { Non-participators } \\
\qquad(n=58)\end{array}$ & $P$ \\
\hline \multicolumn{5}{|l|}{ Health Belief Model } \\
\hline Perceived CRC vulnerability score (1 to 5 ) & $3.5(1.2)$ & $3.7(1.2)$ & $3.1(1.1)$ & 0.0026 \\
\hline Perceived CRC severity score (2 to 10 ) & $7.7(2.0)$ & $7.8(1.9)$ & $7.5(2.3)$ & 0.27 \\
\hline Perceived screening benefits score (6 to 30 ) & $25.6(4.4)$ & $26.6(3.6)$ & $23.6(5.2)$ & 0.0004 \\
\hline Perceived screening barriers score (6 to 30 ) & $14.5(6.0)$ & $12.9(5.6)$ & $17.6(5.6)$ & $<10^{-4}$ \\
\hline Score for motivation to safeguard health (7 to 35 ) & $28.0(4.6)$ & $28.6(4.4)$ & $26.9(4.8)$ & 0.025 \\
\hline Fatalism score (4 to 20 ) & $11.1(4.9)$ & $10.6(4.8)$ & $12.1(4.8)$ & 0.058 \\
\hline \multicolumn{5}{|l|}{ Theory of Reasoned Action } \\
\hline Attitude score (perceived usefulness of screening) (1 to 5 ) & $4.2(1.2)$ & $4.4(1.2)$ & $3.9(1.1)$ & 0.024 \\
\hline Subjective norms(perceived social pressure to perform screening) & $134(88.7)$ & $100(98.0)$ & $34(69.4)$ & $<10^{-4}$ \\
\hline Other preventive or screening behaviours & $158(91.9)$ & $105(92.1)$ & $53(91.4)$ & 1.0 \\
\hline Smoking status & & & & 0.038 \\
\hline Non-smoker & $109(65.7)$ & $79(72.5)$ & $30(52.6)$ & \\
\hline Ex-smoker & $36(21.7)$ & $19(17.4)$ & $17(29.8)$ & \\
\hline Smoker & $21(12.6)$ & $11(10.1)$ & $10(17.5)$ & \\
\hline
\end{tabular}

Quantitative variables: mean, (standard deviation). Qualitative variables: number (percentage)

Missing data: Perceived vulnerability score (4), perceived severity score (3), perceived benefits score (8), perceived barriers score (6), motivation score (6), fatalism score (4), attitude score (10), subjective norms (21), smoking status (6).

ing that they themselves have been adequately informed of the risks by their physicians, must first of all pass on this information to their FDRs. Then these latter must feel themselves to be personally at risk and decide to enrol in a screening programme.

Factors of the HBM, in particular the barriers, the perceived benefits and susceptibility, with the exception of perceived severity, were strongly related to screening behaviour of siblings. These results are consistent with a review of the literature [15] in which, if perceived susceptibility was the most important dimension associated with adopting a preventive behaviour, perceived barriers were the dimension that best explained behaviour, while the influence of perceived severity was very limited. In the context of screening, this may result from the absence of symptoms and of personal experience of the illness concerned. Perceived benefits play a greater role in behaviour when one is already ill than in prevention. Perceived barriers to colonoscopy included the unpleasant nature of the examination, its cost, increased anxiety, the embarrassment of talking about CRC or having to undergo regular screening $[27,28]$ and the time it takes. These results suggest that measures aimed at increasing participation should seek to lower each of the perceived barriers.

The study equally demonstrated the role played by ease of access to colonoscopy in terms of distance to travel and waiting times for targeted screening. Thus, the barriers to undergoing a colonoscopy include cognitive and emotional factors, logistical barriers and barriers relating to the organization of treatment services (geographic location of screening centres and waiting times for appointments).

The study enabled us to take into account the role of the social network in the context of targeted screening, certainly the most difficult area to interpret. It is an important variable in determining behaviour; people with a more extensive social network and more frequent contact with other people are more likely to adopt preventive behaviour (cancer screening) and more likely to engage in health promotion activities (balanced diet, tobacco avoidance) [19], but up until now this variable has rarely been studied in the context of targeted screening for CRC [6], and that before the implementation of the screening recommendations. In this study, the influence of the global structural support provided by the social network could not be satisfactorily interpreted because of the significant amount of missing data. However, the role played by being a member of an association, demonstrated in the United States in individuals at medium risk [19], was also found. Moreover, emotional support emerged as a relevant factor. The part played by social support, and especially family support in this case, should be evaluated in subsequent studies. 
Table 3: Univariate analysis of factors relating to the index patients' siblings' relationships with their physicians, families and friends and the association of these factors with participation in colonoscopic screening.

\begin{tabular}{|c|c|c|c|c|}
\hline & $\begin{array}{c}\text { Total } \\
(\mathrm{n}=172)\end{array}$ & $\begin{array}{l}\text { Participators } \\
\qquad(\mathrm{n}=114)\end{array}$ & $\begin{array}{l}\text { Non-participators } \\
\qquad(\mathrm{n}=\mathbf{5 8})\end{array}$ & $P$ \\
\hline \multicolumn{5}{|l|}{ Medical care } \\
\hline Advice by a physician to undergo screening & $65(40.4)$ & $58(53.7)$ & $7(13.2)$ & $<10^{-4}$ \\
\hline $\begin{array}{l}\text { Score for perceived accessibility of colonoscopy centres } \\
\text { (1 to 5) }\end{array}$ & $3.8(1.2)$ & $4.0(1.2)$ & $3.3(1.1)$ & 0.0011 \\
\hline \multicolumn{5}{|l|}{ Family } \\
\hline Index patient sex: female & $84(48.8)$ & $58(50.9)$ & $26(44.8)$ & 0.45 \\
\hline Index patient age at time of diagnosis & & & & 0.49 \\
\hline$\leq 45$ years old & $22(12.8)$ & $16(14.0)$ & $6(10.3)$ & \\
\hline$>45$ years old & $150(87.2)$ & $98(86.0)$ & $52(89.7)$ & \\
\hline $\begin{array}{l}\text { Number of cases of colorectal cancer declared in first- } \\
\text { degree relatives }\end{array}$ & & & & 0.1 \\
\hline 0 & $45(26.2)$ & $26(22.8)$ & $19(32.8)$ & \\
\hline 1 & $116(67.4)$ & $79(69.3)$ & $37(63.8)$ & \\
\hline$\geq 2 *$ & $11(6.4)$ & $9(7.9)$ & $2(3.4)$ & \\
\hline Discussion about screening with all brothers and sisters & $84(49.7)$ & $73(65.2)$ & $11(19.3)$ & $<10^{-4}$ \\
\hline \multicolumn{5}{|l|}{ Social network } \\
\hline Belonging to a social group & $54(32.0)$ & $41(36.9)$ & $13(22.4)$ & 0.055 \\
\hline Number of contacts with friends or relatives per month & & & & 0.24 \\
\hline$\leq 2$ & $19(12.6)$ & $13(12.6)$ & $6(12.5)$ & \\
\hline 3 to 11 & $98(64.9)$ & $63(61.2)$ & $35(72.9)$ & \\
\hline$\geq 12$ & $34(22.5)$ & $27(26.2)$ & $7(14.6)$ & \\
\hline Structural support score (0 to 4 ) & $2.3(1.1)$ & $2.4(1.1)$ & $2.1(0.9)$ & 0.13 \\
\hline Emotional support score (0 to 4$)$ & $3.4(1.0)$ & $3.5(0.9)$ & $3.2(1.2)$ & 0.039 \\
\hline Material support & $153(91.6)$ & $103(93.6)$ & $50(87.7)$ & 0.24 \\
\hline
\end{tabular}

Quantitative variables: mean, (standard deviation). Qualitative variables: number (percentage)

Missing data: advice by a doctor to undergo screening (11), perceived accessibility score (12), discussion of screening with all brothers and sisters (3), belonging to a social group (3), number of contacts with friends and relatives (21), structural support score (24), emotional support score (1), material support (5).

* 1 individual reported 4 cases of colorectal cancer in FDRs not documented by genetic analysis.

Table 4: Factors favouring siblings' participation in colonoscopic screening according to multivariate logistic regression with cluster effect $(n=138)$.

\begin{tabular}{|c|c|c|c|}
\hline & Adjusted OR & $95 \% \mathrm{Cl}$ & $\mathbf{P}$ \\
\hline Less perceived barriers (score $<14$ ) & 3.2 & {$[1.2-8.5]$} & 0.022 \\
\hline Screening advised by a physician & 4.9 & {$[1.7-13.7]$} & 0.0025 \\
\hline Centres practising colonoscopy perceived as more accessible (score $\geq 4$ ) & 3.2 & {$[1.3-7.8]$} & 0.011 \\
\hline Screening discussed with all brothers and sisters & 3.9 & {$[1.6-9.6]$} & 0.0037 \\
\hline Belonging to a social group & 2.6 & {$[1.0-6.6]$} & 0.044 \\
\hline Age $(<60$ ans $/ \geq 60$ ans $)$ & 1.7 & {$[0.7-4.4]$} & 0.26 \\
\hline Sex (female/male) & 1.3 & {$[0.6-3.0]$} & 0.50 \\
\hline Level of education ( $\geq$ Baccalaureate/< Baccalaureate) & 0.9 & {$[0.3-2.7]$} & 0.86 \\
\hline
\end{tabular}


Randomized trials have been conducted on FDRs of CRC patients using tailored interventions aimed at Health Belief Model factors, in particular perceived barriers to screening. The results suggest that an improvement in screening participation could be obtained from tailored interventions rather than by simply making information about colorectal cancer generally available $[29,30]$.

\section{Conclusions}

Participation of siblings of CRC patients in the recommended screening requires further efforts to be improved. Identification of the multiple factors associated with participation in targeted screening underscores the interest of a global approach including all the stages in the information pathway from the physician, to the index patient and his relatives. Improving the effectiveness of preventive strategies depends on increasing physicians' awareness of the importance of identifying individuals at increased risk and of delivering recommendations about screening, on educating patients and helping them to pass on information about their illness to their relatives and on taking into account the various individual psychosocial factors.

\section{Competing interests}

The authors declare that they have no competing interests.

\section{Authors' contributions}

MT contributed to, performed statistical analysis and prepared the manuscript. II contributed to study concept and design, data acquisition and control, statistical analysis and manuscript edition. MB and VM contributed to study concept and manuscript edition. PI contributed to study concept and design, statistical analysis and manuscript edition, and supervised the study. All authors read and approved the final manuscript.

\section{Acknowledgements}

The authors thank Victoria Champion for allowing them to use her Health Belief Model scale, Laeticia Becq-Giraudon and Nicolas Mériau, clinical research assistants, for data collection and Marian Green for her translation of the manuscript. The French Ligue contre le Cancer and Caisse Nationale d'Assurance Maladie provided financial support.

\section{Author Details}

Public Health; Centre Hospitalier Universitaire de Poitiers; Université de Poitiers; 6 rue de la Milétrie BP 199; 86005 Poitiers Cedex, France, 2Epidemiology \& Biostatistics, INSERM CIC-P 802; Centre Hospitalier Universitaire de Poitiers; Université de Poitiers; 6 rue de la Milétrie BP 199; 86005 Poitiers Cedex, France and 3 Hepatogastroenterology; Centre Hospitalier Universitaire de Poitiers; Université de Poitiers; 6 rue de la Milétrie BP 199; 86005 Poitiers Cedex, France

Received: 21 December 2009 Accepted: 6 July 2010

Published: 6 July 2010

\section{References}

1. Winawer SJ, Fletcher RH, Miller L, Godlee F, Stolar MH, Mulrow CD, Woolf SH, Glick SN, Ganiats TG, Bond JH, Rosen L, Zapka JG, Olsen SJ, Giardiello FM, Sisk JE, Van Antwerp R, Brown-Davis C, Marciniak DA, Mayer RJ: Colorectal cancer screening: clinical guidelines and rationale. Gastroenterology 1997, 112:594-642.

2. Butterworth AS, Higgins JPT, Pharoah P: Relative and absolute risk of colorectal cancer for individuals with a family history: a meta-analysis. Eur J Cancer 2006, 42:216-227.
3. Lieberman DA: Cost-effectiveness model for colon cancer screening Gastroenterology 1995, 109:1781-1790

4. Levin B, Lieberman DA, McFarland B, Andrews KS, Brooks D, Bond J, Dash C, Giardiello FM, Glick S, Johnson D, Johnson CD, Levin TR, Pickhardt P Rex DK, Smith RA, Thorson A, Winawer SJ, American Cancer Society Colorectal Cancer Advisory Group; US Multi-Society Task Force; American College of Radiology Colon Cancer Committee: Screening and surveillance for the early detection of colorectal cancer and adenomatous polyps, 2008: a joint guideline from the American Cancer Society the US Multi-Society Task Force on Colorectal Cancer, and the American College of Radiology. Gastroenterology 2008, 134:1570-1595.

5. ANAES Guidelines Department: Indications for lower gastrointestinal endoscopy (excluding population screening). In Clinical practice guidelines: April 2004 Paris: ANAES; 2004.

6. Madlensky L, Esplen MJ, Gallinger S, McLaughlin JR, Goel V: Relatives of colorectal cancer patients: factors associated with screening behavior. Am J Prev Med 2003, 25:187-194.

7. Harris MA, Byles JE: A survey of screening compliance among first degree relatives of people with colon cancer in New South Wales. Med Screen 1997, 4:29-34.

8. Codori AM, Petersen GM, Miglioretti DL, Boyd P: Health beliefs and endoscopic screening for colorectal cancer: potential for cancer prevention. Prev Med 2001, 33:128-136.

9. Manne S, Markowitz A, Winawer S, Meropol NJ, Haller D, Rakowski W $B a b b J$, Jandorf $L$ : Correlates of colorectal cancer screening compliance and stage of adoption among siblings of individuals with early onset colorectal cancer. Health Psychol 2002, 21:3-15.

10. Longacre AV, Cramer LD, Gross CP: Screening colonoscopy use among individuals at higher colorectal cancer risk. J Clin Gastroenterol 2006 40:490-496.

11. Palmer RC, Emmons KM, Fletcher RH, Lobb R, Miroshnik I, Kemp JA, Bauer $\mathrm{M}$ : Familial risk and colorectal cancer screening health beliefs and attitudes in an insured population. Prev Med 2007, 45:336-341.

12. Ruthotto F, Papendorf F, Wegener G, Unger G, Dlugosch B, Korangy F, Manns MP, Greten TF: Participation in screening colonoscopy in firstdegree relatives from patients with colorectal cancer. Ann Oncol 2007 18:1518-1522

13. Rees G, Martin PR, Macrae FA: Screening participation in individuals with a family history of colorectal cancer: a review. Eur J Cancer Care 2008, 17:221-232

14. Ingrand I, Dujoncquoy S, Migeot V, Ghadi V, Beauchant M, Ingrand P. Interactions among physicians, patients and first-degree relatives in the familial screening of colorectal cancer in France. Patient Prefer Adherence 2008, 2:47-55.

15. Janz NK, Becker MH: The health belief model: a decade later. Health Educ Q 1984, 11:1-47.

16. Champion V: Instrument development for health belief model constructs. Adv Nurs Sci 1984, 6:73-85.

17. Jacobs LA: Health beliefs of first-degree relatives of individuals with colorectal cancer and participation in health maintenance visits: population-based survey. Cancer Nurs 2002, 25:251-65.

18. Ajzen I: The theory of planned behavior. Organ Behav Hum Decis Process 1991, 50:179-211.

19. Kinney AY, Bloor LE, Martin C, Sandler RS: Social ties and colorectal cancer screening among Blacks and Whites in North Carolina. Cancer Epidemiol Biomarkers Prev 2005, 14:182-189.

20. Powe BD: Fatalism among elderly African Americans. Effects on colorectal cancer screening. Cancer Nurs 1995, 18:385-392.

21. Gorin SS: Correlates of colorectal cancer screening compliance among urban hispanics. J Behav Med 2005, 28:125-137.

22. Berkman LF, Melchior M, Chastang JF, Niedhammer I, Leclerc A, Goldberg M: Social integration and mortality: a prospective study of French employees of Electricity of France - Gas of France. The GAZEL cohort. Am J Epidemiol 2004, 159:167-174.

23. Hosmer DW, Lemeshow S: Applied logistic regression. New York: Wiley 1986.

24. Madlensky L, Esplen MJ, Goel V: Reasons given by relatives of colorectal cancer patients for not undergoing screening. Prev Med 2004, 39:643-648

25. Pho K, Geller A, Schroy C: Lack of communication about familial colorectal cancer risk associated with colorectal adenomas (United States). Cancer Causes Control 2000, 11:543-546. 
26. Nieuwenhoff HW Van den, Mesters I, Nellissen JJ, Stalenhoef AF, de Vries NK: The importance of written information packages in support of case-finding within families at risk for inherited high cholesterol. J Genet Couns 2006, 15:29-40.

27. Harris MA, Treloar CJ, Byles JE: Colorectal cancer screening: discussions with first degree relatives. Aust NZ J Public Health 1998, 22:826-828.

28. Rawl SM, Menon U, Champion VL, Foster JL, Skinner CS: Colorectal cancer screening beliefs. Focus groups with first-degree relatives. Cancer Pract 2000, 8:32-37.

29. Glanz K, Steffen AD, Taglialatela LA: Effects of colon cancer risk counseling for first-degree relatives. Cancer Epidemiol Biomarkers Prev 2007, 16:1485-1491.

30. Rawl SM, Champion VL, Scott LL, Zhou H, Monahan P, Ding Y, Loehrer P, Skinner CS: A randomized trial of two print interventions to increase colon cancer screening among first-degree relatives. Patient Educ Couns 2008, 71:215-227.

\section{Pre-publication history}

The pre-publication history for this paper can be accessed here: http://www.biomedcentral.com/1471-2407/10/355/prepub

doi: $10.1186 / 1471-2407-10-355$

Cite this article as: Taouqi et al., Determinants of participation in colonoscopic screening by siblings of colorectal cancer patients in France BMC Cancer 2010, 10:355

Submit your next manuscript to BioMed Central and take full advantage of:

- Convenient online submission

- Thorough peer review

- No space constraints or color figure charges

- Immediate publication on acceptance

- Inclusion in PubMed, CAS, Scopus and Google Scholar

- Research which is freely available for redistribution

Submit your manuscript at www.biomedcentral.com/submit
C Biomed Central 